\title{
Mediações que os professores e alunos estabelecem com o conteúdo da disciplina de Algoritmos de cursos superiores: estudo de caso
}

\author{
Glaucia L. Keidann Timmermann, Fernando J. González \\ Departamento de Humanidades e Educação - Universidade Regional do Noroeste do \\ Estado do Rio Grande do Sul (UNIJUÍ)$$
\text { 98.700-000 - Ijuí - RS - Brasil }
$$ \\ glauciakeidann@gmail.com.br, fernandojaimegonzalez@gmail.com
}

\begin{abstract}
This article is the result of a Master Research in Education in Science that was presented in December 2015 at the Regional University of the Northwest of Rio Grande do Sul State. Its aim was to understand the mediations that teachers and students have with the content Algorithms classes in higher education. Through ethnographic research conducted simultaneously in two distinct classes of this discipline, it was revealed that teachers are teaching techniques and not the development of strategies, which can not stimulate and develop metacognition in students. Can not teach algorithms according to the procedural nature of knowledge seems to be one of the barriers that more difficult for teachers to change the way of working that content in class.
\end{abstract}

Resumo. O presente artigo é o resultado de uma pesquisa do Mestrado em Educação nas Ciências que foi apresentada em dezembro de 2015 na Universidade Regional do Noroeste do Estado do Rio Grande do Sul. Seu objetivo foi compreender as mediações que professores e alunos estabelecem com o conteúdo em aulas de Algoritmos em cursos superiores. Através de pesquisa etnográfica realizada simultaneamente em duas turmas distintas dessa disciplina, foi possível perceber que os professores estão ensinando técnicas e não a elaboração de estratégias, o que pode não estimular $e$ desenvolver o metaconhecimento nos alunos. Não conseguir ensinar Algoritmos de acordo à natureza procedimental desse conhecimento parece ser um dos entraves que mais dificultam aos professores mudar a forma de trabalhar esse conteúdo em aula.

\section{1. $O$ conteúdo de Algoritmos e a motivação da pesquisa}

A disciplina de Algoritmos dos cursos da área de Computação é de suma importância para a formação do profissional desta área, sobretudo para aqueles que irão atuar no desenvolvimento de softwares. Conforme pesquisadores sobre ensino da mesma (SANTOS; COSTA, 2006; BARCELOS; TAROUCO; BERCHT, 2009; ARAÚJO, 
2007), é ela que oferece suporte para boa parte das disciplinas que constituem o núcleo duro da formação de tais cursos.

Seu conteúdo está diretamente relacionado com o desenvolvimento do pensamento lógico ou computacional (GIRAFFA, MULLER e MORAES, 2015) necessário para a elaboração de soluções algorítmicas que, mais tarde ou em concomitante, poderão se tornar programas escritos em diversas linguagens de programação. Além disso, conforme as Diretrizes Curriculares Nacionais dos cursos de Computação $^{1}$, na seção 3 - Projetos Pedagógicos, Organização do Curso e Conteúdos Curriculares, esta explicito que o estudante deve desenvolver a capacidade de compreender os problemas que motivam a escrita de tais soluções automatizadas.

Ao mesmo tempo em que se evidência a relevância da aprendizagem de seu conteúdo, estudos revelam que o componente curricular Algoritmos constitui um dos grandes problemas enfrentados pelos alunos da Computação. Conforme Barcelos, Tarouco, Bercht $(2009$, p.1) seu índice de reprovação é um dos maiores entre as demais disciplinas destes cursos.

Para estes autores, os motivos deste elevado índice estão relacionados diretamente com os processos de ensino e aprendizagem do conteúdo de Algoritmos: os alunos "[...] não apresentam desenvoltura na organização de raciocínios, elaboração de estratégias de resolução de problemas, atenção, concentração, estímulo ao processo de cálculo mental" (BARCELOS; TAROUCO; BERCHT, 2009, p. 1). Os mesmos autores apontam, entre outros problemas, o de ensino-aprendizagem nesta área: ausência de metodologia e didática estimulantes e adequadas ao conteúdo e perfil dos alunos; ausência de objetos de aprendizagem - como softwares educacionais - que despertem o interesse da turma pelo conteúdo e facilitem o entendimento; falta de comprometimento e formação continuada do professor; turmas com muitos alunos em que o professor não consegue dar a atenção individual necessária para que todos estejam com o conhecimento nivelado; falta de consideração por parte do docente de que a turma é heterogênea e por isso as formas de aprender são também heterogêneas; não conferir sentido e aplicação ao conteúdo, deixando-o descontextualizado; ausência de qualquer conhecimento sobre lógica; falta do estabelecimento de uma relação dialógica entre professor e aluno ou mais que dialógica entre professor e colegas, a fim de que o conhecimento possa se dar de formas distintas, entre outros.

Isto ajuda a compreender porque ao mesmo tempo em que o número de cursos da Computação teve crescimento significativo durante a primeira década do século XXI, a quantidade de alunos concluintes reduziu - dados estes revelados no documento Estatísticas da Educação Superior em Computação ${ }^{2}$ da Sociedade Brasileira de Computação (SBC). O percentual de evasão dos cursos superiores na área de tecnologia no Brasil chegou a 82\% conforme pesquisa da Associação Brasileira das Empresas de Tecnologia da Informação e Comunicação (Brascom), publicada na revista Computer World, edição de maio de 2012.

\footnotetext{
${ }^{1}$ Aprovado em 09 de março de 2013, o qual em fevereiro de 2014 - data em que este projeto foi revisado - ainda estava em vigência para cursos da área de Computação.

2 As estatísticas foram construídas a partir de uma base de dados especialmente fornecida pelo INEP, filtrada do CENSO 2011.
} 
Estes fatos motivaram a pesquisa de mestrado (TIMMERMANN, 2015), que é relatada nas próximas seções. Trata-se de um estudo de caso, que analisa as mediações ${ }^{3}$ estabelecidas entre professores, conteúdo e aluno durantes as aulas ministradas para duas turmas do componente curricular Algoritmos, numa universidade do sul do país.

\section{O ensino de Algoritmos e a sua aprendizagem}

$\mathrm{Na}$ classificação das aprendizagens humanas proposta por Pozo (2002), aprender a formular algoritmo é, prioritariamente, do tipo procedimental e refere-se ao saber-fazer, o qual é normalmente aprendido de modo explícito. É um tipo de aprendizagem relacionada com a aquisição e "[...] desenvolvimento das habilidades destrezas ou estratégias para realizar coisas concretas" (POZO, 2002, p. 77).

A aprendizagem dos procedimentos é subdividida em 3 grupos. $\mathrm{O}$ primeiro deles se refere às técnicas ou ações rotineiras que visam sempre ao mesmo objetivo, porém, não se constituem em hábitos aprendidos de modo implícito, de condutas simples. São procedimentos que requerem certo treinamento explícito, baseado numa aprendizagem associativa, por repetição, que deve concluir numa automatização da cadeia de ações, resultando na execução rápida e certeira do processo (POZO, 2002, p. 78).

O segundo grupo se vincula com a aprendizagem de estratégias (POZO (2002, p.78). Procedimentos que se utilizam de técnicas dominadas e recursos disponíveis para resolver problemas. Sua elaboração exige planejamento, tomada de decisões, controle e aplicação de técnicas exclusivas para a situação, pois sempre se utilizam em favor de situações inusitadas e complexas, características de problemas.

A aprendizagem de estratégias é análoga à da elaboração de algoritmo. Por tanto, o conteúdo de Algoritmos é de natureza procedimental e exige algo mais do que o domínio de técnicas, de processos invariáveis e automáticos. Afinal de contas, buscam soluções para situações inusitadas.

$\mathrm{Na}$ maioria das vezes, os problemas diferem entre si e consequentemente suas soluções também. A natureza de cada situação problema é que revelará as técnicas que deverão ser mobilizadas e adequadas na proposição de um algoritmo, o qual nem sempre poderá ser eficiente e eficaz da forma como foi escrito. Nesse momento é necessário refletir sobre as estratégias elaboradas, é dizer, exercitar o metaconhecimento.

Pozo (2002, p. 79) se refere ao metaconhecimento como o terceiro grupo dos resultados da aprendizagem de procedimentos. Este conhecimento permite que o indivíduo seja capaz de regular e manejar a própria atividade de aprendizagem com processos eficazes, pensando, refletindo sobre o próprio conhecimento.

Nesta perspectiva, a pesquisa assumiu os pressupostos teóricos defendidos por Pozo (2002, p. 51-54 e 227-246), no que se refere aos processos cognitivos que subjazem à aprendizagem e seus respectivos desdobramentos pedagógicos. O que leva a trabalhar com a premissa de que o professor que deseja ter êxito em sua missão de

\footnotetext{
${ }^{3} \mathrm{O}$ conceito de mediação é definido como a interação social na aula e o processo de ensino. A primeira delas marca a prática pedagógica desenvolvida em cada turma observada neste estudo de caso e preocupase com variáveis psicossociais da relação pedagógica. A segunda categoria descreve o conjunto de elementos reguladores/intervenientes do/no processo de ensino-aprendizagem de Algoritmos diretamente vinculados ao conteúdo.
} 
ensinar deve estar ciente de quais os resultados que espera que seus alunos aprendam, para que assim, possa adequar seu(s) processo(s) de ensino, considerando também as condições em que esse cenário se (re)constrói. Logo, ter clareza sobre a natureza da aprendizagem necessária a ser ensinada é fundamental para analisar os processos de mediação na sala de aula.

Ensinar algoritmos consiste primordialmente em "colocar em marcha" processos que permitam o aluno ser capaz de elaborar estratégias como soluções para problemas, as quais são escritas na linguagem algorítmica. Para alcançar este objetivo, o professor terá que ensinar técnicas, estratégias e metaconhecimento da forma mais produtiva possível para conseguir uma aprendizagem significativa dos alunos neste campo.

\section{Procedimentos Metodológicos}

A pesquisa desenvolvida foi de aproximação etnográfica e foi subdivida em duas etapas, sendo a primeira de produção dos dados e a segunda de análise dos mesmos.

A coleta dos dados se deu através do acompanhamento de duas turmas de Algoritmos que reunia alunos de diferentes cursos de graduação da área tecnológica durante o primeiro semestre de 2014 na universidade mencionada, sob regência de professores distintos, sendo 12 aulas observadas na turma A, com 30 alunos (maioritariamente do curso de Ciência da Computação) e 11 aulas na turma B, com 28 alunos (da Licenciatura em Matemática e das Engenharias - Civil, Mecânica e Elétrica). Durante esse período foi ministrado todo o conteúdo proposto para a disciplina de Algoritmos, conforme sua ementa: variáveis, constantes, operadores lógicos e matemáticos, estruturas condicionais, estruturas de controle, vetores de uma e de duas dimensões, procedimentos e funções, ou seja, o conjunto de elementos necessários para o desenvolvimento da competência de formular algoritmos básicos computáveis.

Os dados analisados foram produzidos através da gravação do áudio das aulas, de notas de campo e de algumas fotografias. Esses meios de coleta de dados foram de extrema importância para a textualização meticulosa das aulas, resultando em mais de 800 páginas de registros etnográficos, os quais foram analisados numa perspectiva qualitativa.

As aulas transcritas foram sistematizadas em 5 tipos distintos, denominados da seguinte forma: Exposição de conteúdo, Correção de exercícios, Revisão para Avaliação, Avaliação ${ }^{4}$ e Correção de Avaliação, além de alguns momentos dos alunos resolvendo exercícios. Tal organização se deu a partir dos propósitos de cada aula, os quais se repetiram nas turmas $\mathrm{A}$ e B, permitindo a utilização da mesma tipificação em ambas. Tais tipos foram identificados a partir das declarações do professor e a forma como tais encontros foram desenvolvidos.

Os diferentes tipos de aula foram descritos para cada turma, reconhecendo momentos ou fases internas que fossem padrão às mesmas. A base para este processo foi às ações que se repetiam nos tipos de aula nas turmas A e B.

\footnotetext{
4 O termo "avaliação" foi utilizado em sua forma nativa para designar as provas realizadas pelas turmas de Algoritmo ao longo do semestre. Isto é próprio do local da pesquisa, pois ambos os professores denominam "avaliação", tanto o instrumento (prova e/ou trabalho), o processo de verificação da aprendizagem, como o próprio processo de avaliação. .
} 
V Congresso Brasileiro de Informática na Educação (CBIE 2016)

Anais dos Workshops do V Congresso Brasileiro de Informática na Educação (CBIE 2016)

Essas descrições foram sustentadas por excertos retirados dos registros das aulas, com a finalidade de trazer elementos subjacentes dos diferentes episódios captados nas mesmas, permitindo falar sobre uma determinada característica ou propriedade do processo de mediação. Os excertos se constituem de transcrições de áudio, notas de campo, fotografias, reprodução de slides utilizados pelos professores, exercícios propostos como "tema de casa", perguntas das avaliações e trechos de algoritmos.

Em seguida foi feito um segundo movimento de leitura analítica das descrições dos diferentes tipos de aula em cada turma, o que permitiu entender os processos de mediação intrínsecos ao desenvolvimento das aulas. Desta releitura emergiram duas categorias que revelaram e organizaram as mediações que os professores e alunos estabeleceram com o conteúdo nas aulas de Algoritmos, as quais foram denominadas de Interação Social e Processo de Ensino.

A primeira categoria está referida à relação pedagógica estabelecida em cada turma e preocupou-se com variáveis psicossociais da interação professor-aluno. A segunda descreveu o conjunto de elementos reguladores/intervenientes do/no processo de ensino-aprendizagem de Algoritmos vinculados diretamente ao conteúdo.

Para cada uma dessas categorias, foram elencadas e analisadas o que era possível reconhecer como propriedades das mesmas em ambas as turmas. Isto permitiu a elaboração de uma análise por contraste entre A e B. A figura 1 resume as etapas da descrição e análise de dados da pesquisa:

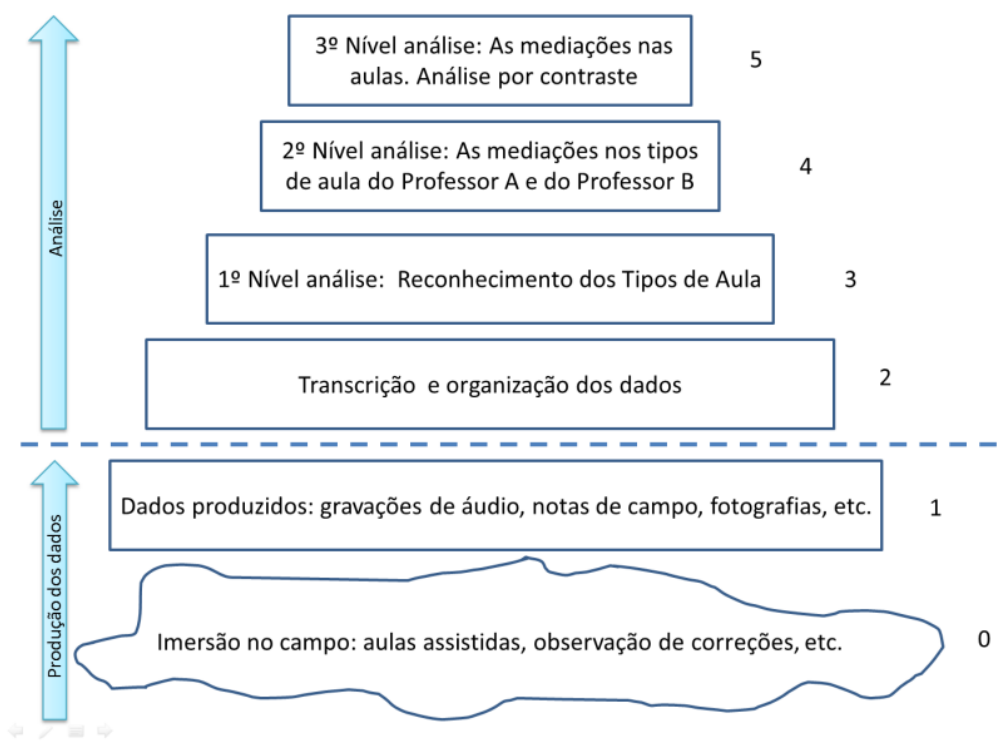

Figura 1. Etapas da descrição e análise dos dados Fonte: Os autores

\section{Análise das mediações observadas nas salas de aula de Algoritmos}

Nesta seção será descrito o estudo de caso destas duas turmas de Algoritmos, através da análise das mediações ocorridas e registradas nas salas de aula observadas. Primeiramente serão discutidos alguns aspectos no que se refere à interação social entre professor e aluno, bem como entre os alunos. Em seguida, serão decompostos e 
analisados também os elementos referentes ao processo de ensino, como este aconteceu entre alunos, conteúdo e professor.

\subsection{Interação Social}

Com base nas descrições do ambiente que caracterizaram estas aulas, construído pela relação professor-aluno, foi possível compreender como alguns elementos da interação social afetam os processos de mediação. Nesse sentido, percebeu-se que num ambiente mais distendido os estudantes parecem se sentirem mais confortáveis para indagar, sugerir, responder e, em definitiva, errar no esforço de compreender o conteúdo.

Isto foi evidenciado nos diferentes tipos de aulas da Turma B. Quando o professor fazia analogias engraçadas para explicar o conteúdo e ou as soluções, os alunos começavam a interagir e expor suas dúvidas, até mesmo a fazer reclamações sobre alguns encaminhamentos didáticos do Professor B.

Foi possível perceber também, que as pequenas conversas aleatórias que o Professor B tecia com os alunos ao chegar à sala, contribuíram para criam um ambiente mais permeável à interação. Esses "bate-papos" mais informais parecem ter contribuído, sobretudo, para descerrar inibições quanto às exposições de dúvidas sobre o conteúdo, que poderiam incidir em incorreções nas formulações/escritas de algoritmos ou incompreensões de conceitos.

Isto também ficou evidente nas aulas de Avaliação na Turma B. Este tipo de aula é naturalmente mais propenso a gerar tensão e normalmente rompe boa parte da relação horizontal entre professor e aluno. No entanto, diante de algumas brincadeiras incitadas pelo Professor B antes e durante a avaliação, alguns alunos riam e até mesmo sentiam-se à vontade para fazer perguntas sobre a resolução das questões, o que já possibilita ao professor conhecer algumas dificuldades remanescentes sobre o conteúdo.

Já um ambiente em que o professor, de forma intencional ou não, estabelece uma relação mais formal, pautado num planejamento no qual parece não haver lugar a potenciais "desvios" gerados pela interação com e dos alunos, restringe os processos de mediação. É o que foi observado na Turma A. As interações por parte dos alunos foram consideravelmente reduzidas em relação à Turma $\mathrm{B}$ e estritamente relacionadas ao conteúdo, a ponto do Professor A questionar se os estudantes estavam "de mal com ele", pois não respondiam seus questionamentos.

\subsection{Processo de Ensino}

Para a análise da categoria processo de ensino se tomou como referência a proposta de Pozo (2002) de tipificação das aprendizagens, particularmente, no que se refere a procedimentos. Analisando as propriedades é possível compreender que mesmo em ambientes de interação social diferentes, com estratégias de ensino que distinguiam em alguns poucos aspectos, tanto o Professor A quanto o Professor B centraram o ensino na aprendizagem de técnicas e não da formulação de estratégias. Propósito que não se alinha natureza conteúdo ensinado.

Nos diferentes tipos de aulas, ficou evidente, com base nos diferentes procedimentos de ensino analisados (explicação, correção, exemplificação, indagação), que tanto o Professor A como o B tinham nas explicações de soluções algorítmicas prontas para alguns exercícios/problemas, sendo estes últimos o vetor central da 
organização do componente. Quando uma questão era corrigida ou revisada (aulas de Correção de Exercícios e Revisão para Avaliação), seu algoritmo era fornecido e explicado minuciosamente, utilizando-se do quadro ou de arquivos em Visual Alg para isto.

Mesmo que os professores fizessem questionamentos as suas turmas, na tentativa de incitá-los a proporem alguma solução, não insistiam nisso e logo na sequência revelavam detalhadamente uma estratégia para o exercício. Essa forma de proceder foi comum a ambos os docentes, sendo que o Professor A foi ainda mais detalhista em suas explanações, do que o B. A pouca insistência na participação dos alunos em concomitante com o fornecimento e elucidação dos algoritmos propiciou que os estudantes compreendessem as soluções algorítmicas, mas não a aprendizagem de sua elaboração.

Outro fato que evidenciou que o ensino dos professores A e B esteve centrado na aprendizagem de técnicas, foi a proposição de extensas listas de exercícios como "tema de casa". Essas listas traziam questões que demandavam dos alunos a implementação de funcionalidades semelhantes aquelas apresentadas nas explanações dos exemplos utilizados para expor o conteúdo (aulas de Explicação de Conteúdos), vez por outra exigindo alguma implementação inédita.

A reprodução destes exercícios nas avaliações de ambas as turmas, fortaleceu a interpretação de que a concepção dos professores sobre a forma de ensinar o conteúdo passava pela aprendizagem de técnicas. Vez por outra eles solicitavam a implementação de uma funcionalidade minimamente distinta daquelas exercitadas, corrigidas e explicadas nas aulas de Correção de Exercícios e Revisão para Avaliação, contudo, nunca foi um aspecto central no processo de mediação.

Some-se a isto, que tanto o Professor A como o B permitiram que os alunos utilizassem algum material para consulta durante a avaliação, nos quais, sempre haviam algoritmos descritos que poderiam ser facilmente adequados às respostas das questões. No máximo demandavam algum conhecimento técnico para transpor a solução, como a alteração de algum nome de variável, de uma instrução de leitura e/ou escrita, de um teste condicional. Questões como essas não avaliam a aprendizagem do conhecimento procedimental estratégico (POZO, 2002, p. 235-241) demandado pela natureza do conteúdo de Algoritmos, mas sim a capacidade reconhecer e usar algumas soluções técnicas conhecidas (explicada pelos professores).

O conhecimento procedimental técnico (POZO, 2002, p. 227-246) é necessário para a elaboração de algoritmos, pois as estruturas e componentes da pseudo-linguagem precisavam ser compreendidas, assimiladas, treinadas e transpostas para as soluções. Porém, não são suficientes para alcançar a aprendizagem demandada pelo objetivo da disciplina e a natureza de seu conteúdo. Na perspectiva teórica assumida (POZO, 2002, p. 234-235), para não ficar apenas com o conhecimento e/ou domínio de algumas técnicas, é necessário que os aprendizes sejam capazes de se depararem com problemas e proporem soluções adequadas ao mesmo, considerando que problemas são diferentes de exercícios.

Para a aprendizagem da elaboração de estratégias é necessário ceder paulatinamente aos alunos as tarefas de selecionar, planificar e avaliar as soluções algorítmicas. Estas atividades demandam e, consequentemente, propiciam o desenvolvimento do metaconhecimento, componente necessário para elaborar e testar as 
estratégias (POZO, 2002, p. 237-241), dimensão também ausente nas experiências de aprendizagem propiciada aos estudantes de ambas as turmas.

Este foi um dos motivos dos alunos das Turmas A e B terem encontrado dificuldade ou não terem conseguido fazer as questões que demandavam aplicação de testes de mesa a códigos nas provas. A grande maioria destes aprendizes não controlaram as soluções sem o auxílio de professores ou colegas, porque não exercitaram sua formulação ao longo de todo o semestre. Em quase todas as aulas as recebiam esmiuçadas.

Conforme Pozo (2002, p. 238-239) o controle de um procedimento estratégico deve ser assumido gradativamente pelo aprendiz. Para tanto, as tarefas de seleção e organização das técnicas envolvidas, aplicação de testes e avaliação de resultados devem ser realizadas inicialmente com o auxilio do mestre/professor e, aos poucos, este transferir aos estudantes a responsabilidade de planificar e executar todas as ações das fases da aprendizagem de estratégias.

Nesse sentido, é importante salientar que as soluções para os exercícios foram analisadas detalhadamente antes dos alunos terem tentado resolvê-los. Os Professores A e B não atinavam em sondar se os estudantes haviam pelo menos tentado fazer tais atividades antes de corrigi-los/revisá-los nas aulas de Correção de Exercícios e de Revisão para Avaliação.

Para capacitar os estudantes a formularem e escreverem algoritmos é necessário que enfrentem/passem por todas as fases de aprendizagem de estratégias (POZO, 2002, 239-239), inclusive aquela onde compreendem o problema e respectivo objetivo da solução a ser formulada. Ambos os professores pouparam os alunos desta última tarefa. Os enunciados dos exercícios e no caso do Professor B até mesmo das questões das avaliações foram explicadas antes das soluções.

Esse enfrentamento das tarefas de cada fase da formulação de um algoritmo deve ser auxiliado pelo mestre e não realizado pelo mesmo, muito menos, ser substituído pela "transmissão" de soluções. Neste sentido, a interação é indispensável neste processo, já que não há possibilidade de mediação sem ela. As incertezas durante a seleção, planificação e as incompreensões dos resultados dos testes, as possíveis reformulações do código devido a erros com os quais os alunos se deparam, não podem ser poupados e necessitam da orientação do professor.

Tal confrontação é inexistente no ensino de técnicas, onde os professores expõem os procedimentos prontos, como ocorreu nas aulas das Turmas A e B. Neste tipo de aprendizagem, a interação pode ser dispensável, visto que os aprendizes são treinados a executar processos já estabelecidos, os quais devem ser apenas condensados para posterior transferência para contextos semelhantes.

Neste sentido, vale salientar algumas atitudes do Professor A. Nas raras vezes que alguns alunos tentaram expor parte de uma solução que criaram ou comentar uma ideia frente à turma, este acabou não valorizando sua interação. Sempre preocupado em "dar conta do conteúdo" e/ou das tarefas planejadas para a aula, acabava encerrando a participação com breves frases.

Este fato remeteu a concepção de que a interação dos alunos era considerada dispensável para o professor. Parecia compreender que participações como essas não eram importantes para a aprendizagem e que os estudantes deveriam apenas prestar 
atenção as suas explicações sobre o conteúdo e das soluções para que aprendessem elaborar algoritmos que seriam reaplicados nas avaliações.

Diante dessas atitudes do mestre, os aprendizes podem compreender que devem memorizar as soluções e não elaborá-las. Essa ideia pareceu ter sido absorvida pelos alunos das Turmas A e B que interagiam nas aulas. Suas participações se resumiram a dúvidas sobre as soluções explanadas pelos professores nas aulas de Explicação de Conteúdos, Correção de Exercícios e Revisão para Avaliação, e até mesmo de Correção de Avaliação. Na maioria das aulas observavam e escutavam atentamente as explicações, copiando os códigos no caderno ou em arquivos de Visual Alg, assimilando apenas a sintaxe das instruções.

Além disso, quando a interação se torna dispensável para o professor, existe uma grande possibilidade deste não se aperceber das dificuldades ou incompreensões de alguns alunos, sejam elas sobre a aprendizagem de técnicas ou de elaboração de estratégias, limitando, por conseguinte, as possibilidades de mediação. Foi o que aconteceu nas Turmas A e B. Em ambas, houve os dois grupos distintos de alunos no tocante a interação: o que participava nas aulas durante as explanações dos professores e o que não participava. Na Turma $\mathrm{B}$ isto apareceu com muito mais força do que na $\mathrm{A}$, pois o número dessas interações era maior.

Estes alunos, a maioria sentados no fundo da sala, apresentavam muitas dificuldades no tocante ao aprendizado do conteúdo, o que aparecia, sobretudo, nas avaliações. No entanto, como não interagiram durante as aulas, os motivos dessas dificuldades permaneceram desconhecidos.

O Professor B até tentou uma aproximação na aula de Correção de Avalição, quando entregou a primeira prova individualmente, mas apenas ouviu reclamações. Após essa, nenhuma outra ação especial foi tomada pelos professores A e B para fazer com que o grupo de alunos que não interagia durante as explanações coletivas, participasse.

$\mathrm{Na}$ Turma A, alguns destes ainda chamavam o professor para lhes auxiliar individualmente. Esse tipo interação pareceu ser a preferida pelos mesmos. Mas na Turma B, estes estudantes pareceram "atores coadjuvantes de um filme", que entravam em cena, apenas nas aulas de Correção de Avaliação.

A interação individual, entre o professor e um destes alunos, poderia propiciar um ambiente mais favorável para a interação e consequente aprendizagem. Uma possibilidade a ser investigada é que estes alunos não se sintam cômodos para expor suas dúvidas e erros frente ao grande grupo.

A forma de proceder nas aulas de Correção de Avaliação também reforçou a ideia do ensino de técnicas nas turmas $\mathrm{A}$ e $\mathrm{B}$. Isto porque desencadearam processos de correção muito semelhantes aos das aulas de Correção de Exercícios e Revisão para Avaliação. Os professores de ambas as turmas explanavam minuciosamente as soluções, com a diferença de que o Professor A preferia verbaliza-las fazendo o registro dos trechos principais do código no quadro e o $\mathrm{B}$, normalmente registrava os algoritmos por completo, e ainda os submetia a testes. Mais uma vez, a forma de proceder incitou os alunos a copiar as soluções e assimilar as mesmas.

Durante todo o semestre de Algoritmos, em ambas as turmas, apenas o trabalho em Mat Lab pareceu outorgar aos alunos ações que os incitariam a elaborar soluções 
algorítmicas. Mesmo os professores A e B tenham explicado os enunciados das três diferentes opções de programas - dentre as quais os estudantes deveriam escolher uma para desenvolver - poupando os alunos de sua tarefa de compreender o problema, não apresentaram um algoritmo semelhante ao esperado como resposta, o que já se constituía em um costume. Desta vez, apenas explicaram um exemplo de código, que nada tinha a ver com qualquer uma das opções de trabalho.

Talvez não tenha sido uma boa escolha para a aprendizagem do conteúdo de Algoritmos, a introdução da linguagem de programação Mat Lab nas aulas finais, como o que aconteceu. Isto porque, alguns alunos da turma nem mesmo haviam aprendido a aplicação e representação de estruturas e elementos no Visual Alg, estando ainda nas fases iniciais da aprendizagem de técnicas, e na sequência deveriam assimilá-las em formato um tanto distinto, num período de tempo pequeno (duas aulas apenas).

Além disso, alguns alunos não compreendiam o motivo de terem que aprender a elaborar Algoritmos, sobretudo na Turma B. Reclamavam não significar sua aplicação, sobretudo quando faziam os exercícios. Muitos destes apresentavam "problemas" que não necessitavam de soluções algorítmicas. A automatização parecia dispensável, pois se constituíam em processos simples e que não repetitivos.

Não é conveniente aprender um processo técnico sem significar seu uso (POZO, 2002). Para que seja selecionado, testado, e adequado à solução, é necessário compreender sua usabilidade.

Cabe ainda um comentário sobre o tipo de problemas que a aprendizagem do Algoritmos permite ou deve resolver que, não pode ser confundido com a solução do problema a ser computado. Há um fato observado durante as aulas de Correção de Avaliação na Turma B que indicou uma possível confusão ou falta de percepção deste professor. Em algumas questões que envolviam o conhecimento de fórmulas/processos matemáticos, absteve-se de fornecer as mesmas para os estudantes. Esta ação foi diferente da forma como procedia nas aulas de Correção de Exercícios e Revisão para Avaliação. Sempre relembrava/explicava estes procedimentos antes de explicar a solução. Pareceu compreender que os alunos deveriam montar tais cálculos, visto que os considerava "simples" para graduandos.

O aluno de Algoritmos necessita aprender a elaborar soluções algorítmicas e não matemáticas ou de qualquer outra área. Certamente que tais estratégias envolverão processos dos mais diversos âmbitos, porém, não é da alçada dos desenvolvedores da área da Computação dominar os mesmos. Estes profissionais terão de aprendêlos/conhece-los à medida que se fizerem necessários, consultando outros profissionais das respectivas áreas ou pesquisando sobre as mesmas. Não diferenciar essas dimensões (solução da área, solução algorítmica), parece ter dificultado mais ainda a compreensão do conhecimento específico da disciplina.

\section{Conclusões}

Em síntese, a qualidade das mediações que professores e alunos estabelecem com o conteúdo em disciplinas no curso de computação é sustentada tanto na interação social, como na organização do ensino. A interação social positiva, que cria um ambiente propício para a participação dos alunos em aula, é facilitadora do processo mediação. Contudo, ficou evidente, que não se resolvem as dificuldades criadas por ensino centrado num resultado de aprendizagem que não se alinha com a natureza do 
V Congresso Brasileiro de Informática na Educação (CBIE 2016)

Anais dos Workshops do V Congresso Brasileiro de Informática na Educação (CBIE 2016)

conhecimento ensinado. Dessa forma foi constatado nesta pesquisa que organização do ensino é decisiva na possibilidade efetiva dos estudantes aprenderem a pensar algoritmicamente. Se infere que para propiciar aprendizagens no componente Algoritmos é necessário pensar o ensino sustentado em processos de mediação que considerem a natureza específica do seu conteúdo, bem como se favoreça um ambiente centrado no desenvolvimento compartilhado de estratégias e que propicie interações entre professor e aluno, não apenas na compreensão e memorização de técnicas.

\section{Referencias}

Barcelos, R. JS; Tarouco, L.; Bercht, M. O uso de mobile learning no ensino de algoritmos. Universidade Federal de Goiás. Instituto de Informática. Tablets PCs Algorithms/Programming. Universidade Federal do Rio Grande do Sul. Revista Renote, v. 7, n. 3. 2009.

Brasil. Ministério da Educação. Conselho Nacional de Educação. Diretrizes Curriculares Nacionais para os Cursos de Computação. Brasília: MEC, 2012. Disponível em $<$ http://portal.mec.gov.br/index.php?option=com_content\&view=article\&id=12991 $>$. Acesso em $<19$ JUL2013 $>$.

Brasil, Parâmetros Curriculares Nacionais para o Ensino Médio (PCNEM). Língua Portuguesa. Área de Linguagens, códigos e suas tecnologias. Brasília: MEC/SEF, 1998.

Giraffa, L. M. M.; Muller, L.; Moraes, M. C. Ensinando Programação apoiada por um ambiente virtual e exercícios associados a cotidiano dos alunos: compartilhando alternativas e lições aprendidas. In: IV Congresso Brasileiro de Informática na Educação e X Conferência Latino-Americana de Objetos e Tecnologias de Aprendizagem, Maceió, Alagoas, Brasil. Workshop do IV Congresso Brasileiro de Informática na Educação (CBIE 2015): SBC, 2015.p. 1330-1339.

Pozo, J. I. Aprendizes e mestres: a nova cultura da aprendizagem. Porto Alegre: Artmed, 2002.

Santos, R. P. dos S.; Costa, H. A. X. Análise de Metodologias e Ambientes de Ensino para Algoritmos, Estruturas de Dados e Programação aos iniciantes em Computação e Informática. In: INFOCOMP Journal of Computer Science, vol. 5, no. 1, pp.41-50, 2006.

SBC. Educação Superior em Computação Estatísticas 2011. Disponível em < http://www.sbc.org.br/index.php?option=com_jdownloads\&Itemid=195\&task=view. download\&catid=39\&cid=1479>. Acesso em <31JUL2013>.

Timmermann, G. L. K. O desafio de aprender e ensinar algoritmos: mediações que professores e alunos estabelecem com o conteúdo em disciplinas do curso de Computação. 15 de dezembro de 2015. 524 f. Dissertação (Mestrado em Educação nas Ciências) - Universidade Regional do Noroeste do Estado do Rio Grande do Sul (UNIJUÍ), Panambi. 2015. 